\title{
Who Owes the Therapists?
}

The formation of the Society of Sports Therapists challenges BASM to have a rational view on the role of the non-medical fraternity in sports medicine. Growing public interest in sport, exercise and health are a natural consequence of the Sports Council's long commitment to 'Sport for All' and there is increasing interest in careers in this field. Orthodox medicine's disinterest has left a vacuum for others to exploit.

What is a 'Sports Therapist'? Graham Smith's article sets out his organization's stall. An ambitious syllabus lasts 24 days for candidates with a minimum entry of 18 years of age and a First Aid certificate. This aims primarily at sports injury management. Other organizations claim this 'trainer' title and one, for instance, has an established syllabus, for entrants with four GCSE passes, leading to certification in a full-time course of three terms costing $£ 3600$, which encompasses a wide range of alternative health therapies. This targets the lucrative health and fitness market, including clubs and hotels. Both courses aspire to validation by the National Council for Vocational Qualifications.

The SST's offer of fully fledged professional status with indemnity insurance and detailed advice on financial and advertising behaviour suggests that sports therapists may envisage open public advertising of private High Street sport clinics without medical, or even supplementary professional, cover. It should be made clear whether this is the case - and if so, for 18 year-olds with a 24-day course to their credit as well as more qualified members who choose also to join the SST and are already bound by their own professional codes. As many are already disquited by the volume of public self-advertisement by physiotherapists grasping the earning potential of the sports injury trade, the idea of a further tier of unsupervized medical attendants may not be seen as being clearly in the public interest and this is already reflected in BASM's criteria for inclusion in its Annual Sports Clinic register.

Chartered physiotherapists are threatened by these developments, which stem in part from their inability to have fought for protection of title. There are other 'physiotherapists' (plenty of them in sport already), now 'therapists' whose early courses featured treatment modalities of complexity and potential danger which Chartered Physiotherapists take three years to learn. The issues go further, but raise the underlying question of how 'multidisciplinary' a professional organization can be and still satisfy both its members and the public whose interest it must safely serve.

Should BASM play a part - or is it none of its business what others do within the law, however deficient that law in clinical issues? If BASM has a legitimate interest, is it simply to help educate others on request? Is the public's confusion due to constraints hitherto on only the doctors' advertising?

Should BASM evolve further to become a broader national organization accommodating all groups interested in sports medicine (however defined)? Can BASM emulate, for instance, the Australian Sports Medicine Federation in its espousal of the whole spectrum of 'sports medicine' within a strong organization which sets standards for a multi-tiered membership or is it to serve only state-registered medical groups?

The interests enthusiasm and dedication of the lay groups becoming 'trainers' and 'therapists' is real and shores up sport. To ignore it is to encourage unguided excesses of enthusiasm. BASM has often talked of lay education programmes but been too underfunded and overstretched to provide them. A choice lies between leaving each faction to its own affairs and of seeking ways of cooperating to the greater good.

Teachers don't easily influence those they ignore. 